Resumo

Este artigo insere-se em uma linha de estudos cujo objetivo é refletir sobre a experiencia da fome na infância e suas possiveis relações com o processo de constituição psiquica. Apresentaremos aqui um recorte dos resultados da aplicação do instrumento Avaliação Psicanalítica aos 3 anos (AP3), realizada em uma instituição do terceiro setor da cidade de Fortaleza, estado do Ceará, referência no tratamento da desnutrição infantil. Com a análise, pôde-se relacionar a prevalência dos quadros de desnutrição aos processos de estabelecimento da demanda, levando em consideração que a privação do alimento pode ter como correlato, paradoxalmente, a sua recusa. Descritores: desnutrição infantil; fome; demanda; recusa alimentar; avaliação psicanalítica aos 3 anos.

\section{PRIVAÇÃO DO ALIMENTO \\ E INCIDÊNCIAS NA \\ CONSTITUIÇÃO PSÍQUICA: \\ UM ESTUDO SOBRE O \\ ESTABELECIMENTO DA \\ DEMANDA EM CRIANÇAS \\ DIAGNOSTICADAS COM \\ DESNUTRIÇÃO A PARTIR \\ DA APLICAÇÃO DA \\ AVALIAÇÃO PSICANALÍTICA AOS TRÊS ANOS}

Karla Patrícia Holanda Martins

Maria Celina Peixoto Lima

Gabriela Monteiro Simão

Allan Ratts de Sousa

DOI: http//dx.doi.org/10.11606/issn. 1981-1624.v21i3p618-638

- Psicanalista. Pós-doutorado no Instituto de Psicologia da Universidade de São Paulo, bolsista de pós-doutorado Sênior do Conselho Nacional de Desenvolvimento Científico e Tecnológico (CNPq). Professora adjunta da Universidade Federal do Ceará (UFC),

Fortaleza, CE, Brasil.

- - Psicanalista. Professora do Programa de Pós-Graduação em Psicologia da Universidade de Fortaleza (Unifor), Fortaleza, CE, Brasil.

- a - Psicanalista. Mestranda em Psicologia pela Universidade Federal do Ceará (UFC), bolsista de mestrado da Fundação Cearense de Apoio ao Desenvolvimento Científico e Tecnológico (Funcap), Fortaleza, Ceará, Brasil.

- " - Psicólogo. Graduado pela Universidade Federal do Ceará (UFC), Fortaleza, Ceará, Brasil. 


\section{Introdução}

A

ste artigo está inserido em um conjunto de estudos que partem da perspectiva de incluir, junto aos aspectos socioeconômicos, as dimensões subjetivas e simbólicas que perpassam as questões da fome e da desnutrição infantil nas situações de extrema pobreza (Carvalho, Lima \& Martins, 2013a, 2013b; Martins, 2006, 2010, 2014; Martins et al., 2011). Será aqui apresentado um recorte dos resultados da pesquisa intitulada Saúde mental e constituição psíquica: contribuições da psicanálise ao campo da saúde coletiva ${ }^{1}$, realizada no Instituto da Primeira Infância (Iprede), localizado na cidade de Fortaleza, Ceará, instituição que se tornou referência pelo trabalho que realiza, há três décadas, no campo da desnutrição infantil.

A partir do pensamento freudiano, tem-se a alimentação do bebê como paradigma de uma experiência que organiza fronteiras corporais e psíquicas reguladoras de formas de identificação e de relações primárias com a alteridade. Impossibilitado de promover as ações específicas capazes de aplacar suas necessidades vitais, dentre elas a fome, o ser humano é marcado, originariamente, por uma dupla dependência em relação ao semelhante: que lhe ofereça o alimento para sua sobrevivência orgânica, mas, além disso, que lhe introduza no universo simbólico e social. Dessa forma, a alimentação, para a psicanálise, está associada à inauguração da condição desejante do homem (Martins et al., 2011).

Na pesquisa que será apresentada utilizou-se como metodologia a aplicação do instrumento denominado Avaliação Psicanalítica aos 3 anos (AP3) com dezesseis crianças que estavam sendo atendidas no Iprede em função de quadro clínico de desnutrição. Com o trabalho de avaliação psicanalítica, foi possível pensar as problemáticas alimentares da primeira infância e suas relações com os processos de constituição psíquica, em particular, a partir do eixo teórico-clínico do estabelecimento da demanda, proposto pelo referido instrumento (Kupfer et al., 2008, 2010). O destaque dado a tal eixo decorre da incidência, testemunhada pelas entrevistas, de impasses na relação mãe-criança, mediada pela oferta do alimento, o que nos leva a interpretá-los como sintomáticos da operação identificada por Lacan como estabelecimento da demanda. Com base ainda em nosso referencial teórico e em pesquisas desenvolvidas anteriormente (Carvalho, Lima \& Martins, 2013a; 2013b), neste artigo, daremos destaque à discussão da construção da demanda em articulação com os processos primários de identificação e as problemáticas especulares mãe-criança. Todavia, inicialmente, consideraremos o contexto de estudos e políticas públicas que tratam da desnutrição, apontando seus fatores determinantes e suas relações com a pobreza. 


\section{Desnutrição e políticas públicas}

Seguindo as orientações da Organização Mundial de Saúde (OMS), as políticas públicas sobre alimentação e nutrição infantis, consolidadas nos últimos 30 anos, têm concentrado seus esforços no combate à desnutrição e no incentivo ao aleitamento materno. A desnutrição é, ainda, direta ou indiretamente responsável por cerca de um terço das mortes entre crianças menores de cinco anos (World Health Organization [WHO], 2009), embora dados do The State of Food Insecurity in the World (Food and Agriculture Organization of the United Nations [FAO], 2015) apontem um decréscimo nos números relacionados à desnutrição causada pela fome no mundo.

Nas classificações biomédicas, a desnutrição é considerada uma síndrome cujas manifestações clínicas se expressam através de déficits a níveis metabólicos e antropométricos. $\mathrm{O}$ quadro é associado a uma "natureza clínico-social multifatorial cujas raízes se encontram na pobreza" (Brasil, 2005).

No Brasil, importantes avanços nas políticas públicas de combate à fome e à pobreza devem ser considerados, principalmente a partir do marco da incorporação da alimentação como um direito social. Com a Lei Orgânica no 8.080/1990, a alimentação e a nutrição passam a ser tratadas por essas políticas como fatores condicionantes e determinantes sociais de saúde, ou seja, uma alimentação adequada depende não somente do acesso a quantidades suficientes de nutrientes, mas de uma rede articulada de políticas e serviços que proporcionem o desenvolvimento social da população.

Nas últimas décadas são apontadas melhorias substanciais nos indicadores de saúde e nutrição, principalmente na infância (Cavalcante e Silva, 1995; Brasil, 2012; Cavalcante e Silva et al., 2015). O país seguiu as metas da Declaração do Milênio de 2000 (Organização das Nações Unidas [ONU], 2001), nas quais se previam, dentre outras, a redução das taxas de pobreza, de fome, de doenças infecciosas e de mortalidade materna e infantil até 2015 . No entanto, estas melhorias ocorreram de forma desigual nas principais regiões geográficas do país (Correia et al., 2014a).

O estado do Ceará possui prevalência do clima semiárido, que abrange 95\% do seu território, e população de mais de oito milhões de habitantes. Cerca de $85 \%$ da população do estado utiliza o Sistema Único de Saúde (SUS), que tem conseguido expandir a atenção básica à saúde por meio do Programa Saúde da Família (Correia et al., 2014a). Os programas governamentais de seguro social, incluindo a complementação de renda, garantiram, ao longo das duas últimas décadas, a subsistência de muitas famílias, tanto na capital, Fortaleza, quanto no interior do estado. 
Fenômenos de transição demográfica, epidemiológica e nutricional têm sido registrados, desde 1987, por uma série de Pesquisas de Saúde Materno-Infantil no Ceará (Pesmics), coordenada por um grupo de professores da Universidade Federal do Ceará (UFC). As seis pesquisas realizadas constituem instrumento de acompanhamento da situação de saúde e das políticas públicas no estado. Importantes mudanças em indicadores demográficos e de saúde foram observadas nesse período, incluindo redução de $81 \%$ na taxa de mortalidade infantil, aumento de $43 \%$ na taxa de aleitamento materno e realização de uma taxa de imunização de $95 \%$ (Cavalcante e Silva et al., 2015). Cabe ressaltar que este processo foi iniciado no estado nos idos dos anos 1980, a partir da proposta matriz nascida no interior, no município de Jucás, com a pioneira experiência dos agentes comunitários de saúde.

As Pesmics também permitiram a análise específica de indicadores de desnutrição na infância. $\mathrm{O}$ artigo "Prevalence and determinants of child undernutrition and stunting in semiarid region of Brazil" (Correia et al., 2014b) demonstra o resultado da avaliação dos dados das Pesmics de 1987 e de 2007, referentes à evolução da prevalência e os determinantes da desnutrição em crianças no estado do Ceará.

Foram coletados, além dos dados nutricionais, os fatores socioeconômicos e demográficos, que incluíram: características socioeconômicas e demográficas (renda familiar, disponibilidade de água, disponibilidade de sanitários); acolhimento das crianças (aleitamento materno, pai vivendo com a família e educação da mãe); cuidados de saúde (criança possui um cartão de saúde, consultas médicas, vacinação); características biológicas (idade, sexo, nascimento, peso) e história de morbidade (hospitalização por diarreia, pneumonia etc.).

Os resultados da comparação dos dados das Pesmics de 1987 e de 2007 apontaram que a prevalência de desnutrição aguda foi reduzida em $60 \%$, passando de $12,6 \%$ em 1987, para 4,7\% em 2007. O grupo concluiu que o desenvolvimento socioeconômico, com maior acesso à renda, além do maior acesso às intervenções de saúde, parecem ter efetivamente contribuído para a melhoria do estado nutricional das crianças.

Em grande parte dos estudos, a desnutrição infantil aparece associada à discussão sobre a diminuição da fome e da pobreza e seus determinantes sociais e econômicos, não se estendendo, todavia, à análise de fatores subjetivos envolvidos em suas etiologias e persistências. Relembre-se estudo realizado nos anos 1980 que 
sugeria os seguintes determinantes relacionados à mortalidade infantil e à desnutrição: "as características biológicas da mãe, as condições socioeconômicas da família e a disponibilidade e qualidade da assistência médica" (Bobadilha, 1988, citado por Cavalcante e Silva, 1995, p. 160).

Deste modo, como inicialmente anunciado, o presente artigo, faz parte de um conjunto de investigações que se propõe a pensar sobre os possíveis efeitos subjetivos da experiência da fome no estado do Ceará (Martins, 2006). Entre 2006 e 2009, o estudo foi estendido ao universo da infância, sendo proposta uma pesquisa longitudinal com crianças entre quatro e seis anos que haviam sido internadas durante o primeiro ano de vida com quadros de desnutrição moderados e graves no Instituto da Primeira Infância (Iprede). Na ocasião, as estratégias de sobrevivência psíquica construídas pelas crianças e suas famílias para agenciar a magnitude desta experiência foram pensadas considerando-se as relações entre fome e dor psíquica e suas possíveis incidências sobre o desenvolvimento da linguagem, em particular as relacionadas à fala e ao brincar (Martins et al., 2011).

A continuidade dos estudos revelou que nem sempre o que estava em primeiro plano na desnutrição era uma privação real do alimento sofrida diretamente pela criança (Carvalho, 2011; Carvalho et al., 2013a, 2013b; Martins et al., 2011). Apesar de, em alguns casos, a desnutrição aparecer associada à privação efetiva do alimento, Carvalho (2011) observou o importante aspecto de que a desnutrição surgia também como consequência de uma recusa em comer, o que se dava, muitas vezes, em seguida ao processo de desmame e, portanto, de separação. Assim, propõe:

O que algumas [mães] denunciavam em suas falas era que a questão não era a falta real de alimento para oferecer aos seus filhos desnutridos, mas uma resistência desses em se alimentar, assim como uma dificuldade delas em saber o que eles queriam.... Quando perguntadas sobre a história da desnutrição dos filhos, relatavam que o início da perda de peso coincidia com o período do desmame, bem como expressavam suas dificuldades em lidar com a recusa da criança em relação aos alimentos sólidos (Carvalho, 2011, p. 21).

Em 2012, a fim de dar prosseguimento às investigações a respeito de possíveis vicissitudes da experiência da fome para a constituição psíquica, em articulação com os processos de separação mãe-criança, a presente pesquisa foi iniciada. Como anteriormente anunciado, o seu encaminhamento metodológico foi centrado na aplicação da AP3.

622 Estilos clin., São Paulo, v. 21, n. 3, set./dez. 2016, 618-638. 
A partir daquilo que pôde ser observado nas entrevistas, destacamos o eixo referente ao estabelecimento da demanda na criança e suas relações com os processos primários de identificação como operadores de leitura das problemáticas nutricionais e relacionais por elas apresentadas. Durante as entrevistas, os impasses observados na relação mãe-criança revelaram, em primeiro plano, as dificuldades da mãe de traduzir em palavras as ações das crianças, tomando-as como apelo. $\mathrm{O}$ silêncio das mães parecia inversamente proporcional à agitação motora das crianças e as dificuldades relacionadas à conquista da fala por parte destas.

\section{Considerações metodológicas}

O Iprede, inserido na rede do SUS, realiza atividades clínicas e de assistência social a partir de uma equipe multidisciplinar, em regime ambulatorial. As crianças ingressam na instituição na faixa etária de zero a seis anos, geralmente encaminhadas por profissionais das Unidades Básicas de Saúde ou por demanda espontânea, preponderantemente por quadros de desnutrição ou risco nutricional ${ }^{2}$.

$\mathrm{Na}$ composição da amostra, os seguintes critérios de inclusão foram respeitados: crianças com idade entre três e três anos e onze meses, acompanhadas por seus respectivos cuidadores, que estavam em atendimento na instituição há menos de um ano. Adotou-se como critério de exclusão crianças que não se adequavam aos critérios anteriormente mencionados e aquelas que apresentavam comorbidades neurológicas. Vale ressaltar que se incluiu como critério selecionar as crianças que estavam sendo acompanhadas há menos de um ano, pois, nesses casos, poderíamos observar justamente as manifestações de crianças que não haviam ainda passado por um longo período de intervenção clínico-institucional.

Nos últimos anos, no Brasil, estudos e publicações voltados para a detecção e intervenção precoce vêm se tornando cada vez mais numerosos (Bernardino, 2006; Jerusalinsky, 2008; Kupfer et al., 2010; Teperman, 2005). Destaca-se a Pesquisa Multicêntrica de Indicadores de Risco para o Desenvolvimento Infantil realizada no período de 2000 a 2008 com o objetivo de selecionar indicadores a serem incluídos na Ficha de Acompanhamento do Desenvolvimento de crianças de zero a cinco anos, do Ministério da Saúde. Esta pesquisa foi realizada a partir da construção de dois instrumentos: o IRDI (Indicadores de Risco para o Desenvolvimento Infantil), composto por 31 indicadores observáveis nos primeiros dezoito meses de vida da criança, e a AP3 (Avaliação Psicanalítica aos 3 anos). $\mathrm{Na}$ ocasião, a AP3 foi proposta para permitir a validação do IRDI, mas mostrou-se eficaz ao ser aplicada 
isoladamente, em razão da importância que ela apresentou como instrumento sinalizador da presença de sintomas clínicos (Jerusalinsky, 2008; Di Paolo, Lerner \& Kupfer, 2008; De Césaris, 2013; Kupfer et al., 2010; Bernardino \& Vaz, 2015).

O conjunto de indicadores do IRDI foi estabelecido a partir dos seguintes eixos teóricos: suposição do sujeito, estabelecimento da demanda, alternância presença/ausência e função paterna, os quais são considerados como operações fundamentais formadoras do psiquismo. A AP3 instituiu, partindo desses quatro eixos, as seguintes formações do inconsciente pelas quais poderiam ser observados sintomas clínicos: o brincar e a fantasia; o corpo e sua imagem; manifestação diante das normas e posição frente à lei; e fala e posição na linguagem (Jerusalinsky, 2008).

As nossas avaliações seguiram o roteiro proposto pela Pesquisa Multicêntrica de Indicadores de Risco para o Desenvolvimento Infantil (Kupfer et al., 2008, pp. 137-147). As entrevistas foram realizadas, em sua maioria, com a mãe e a criança. O pai esteve presente em apenas uma das avaliações. Em três delas constou-se a presença de um irmão. Em uma delas a avó esteve presente.

Os achados após a aplicação da AP3 indicaram que os sintomas clínicos mais presentes foram os relacionados ao corpo e sua imagem e à fala e posição na linguagem. Supõe-se que as dificuldades alimentares, verificadas 
durante as aplicações, denotam importante relação com o estabelecimento da demanda, pois os indicadores desse eixo representam o enodamento do corpo ao registro pulsional, o que estará na base de toda a atividade posterior de linguagem e da relação com os outros, funcionando junto à suposição de sujeito como uma operação fundamental para a matriz da constituição do narcisismo.

No eixo estabelecimento da demanda (ED) "estão reunidas as primeiras reações involuntárias que o bebê apresenta ao nascer, tais como o choro, e que serão reconhecidas pela mãe como um pedido que a criança dirige a ela" (Kupfer et. al., 2010, p. 52. Esse reconhecimento possibilitará a construção de uma demanda - para a psicanálise, sempre uma demanda de amor (Lacan, 1992). A partir do referencial lacaniano, o conceito de demanda refere-se à expressão de um apelo quando se objetiva obter algo de alguém. Portanto, no humano, a demanda, operando para além do registro da necessidade, estaria relacionada à ressignificação do objeto perdido da primeira experiência de satisfação, reencontro impossível que coloca em jogo, sobretudo, a demanda de amor.

Em outras palavras, a demanda consiste na preservação da função do desejo. Afirma Lacan (1992, p. 202): "A ambivalência primeira, própria a toda demanda, é que, em toda demanda, é igualmente implicado que o sujeito não quer que ela seja satisfeita”. Deste modo, a demanda forma-se em um circuito que inclui sempre o Outro e que perpassa também o bebê e os outros que o cercam. É uma operação que provém da leitura que esses outros fazem acerca das ações do bebê, mas também de como o próprio bebê perceberá e, para além disso, interpretará essa leitura. A partir daí, o bebê deseja pela mediação de uma demanda endereçada ao Outro. Como continuará afirmando Lacan (1992, p. 201-202) a sensação de fome é o resultado de uma equação que tenciona duas operações: "a demanda de ser alimentado" e a "demanda de se deixar alimentar".

Em seguida, faremos a leitura de algumas situações clínicas provenientes das aplicações da AP3 tendo como norte o conceito de demanda. Para a discussão foram retomadas as sugestões do roteiro como chave de leitura dos resultados de aplicação da AP3 (Kupfer et al., 2008, p. 137-147), especificamente no que se refere ao estabelecimento da demanda. Foram observados os seguintes aspectos na relação entre os pais e a criança: Como os pais tomam a demanda da criança? Tomam-na ao pé da letra ou supõem algo além dela? Quando a criança lhe dirige demandas, os pais tentam saber do que 
se trata, interrogam o filho, propõem hipóteses? Frente às demandas do controle dos esfíncteres, quais foram as interrogações? Os pais estão interessados nas descobertas da criança? Nas situações de alimentação, como a criança reage? Os pais dirigem demandas à criança ou só dão ordens? A criança mostra interesse em compartilhar com os pais as suas descobertas ou se isola? Já no que se refere à entrevista com a criança, foram observadas as formas através das quais se relacionou com o entrevistador e, principalmente, como, na transferência, formulou seus pedidos. Como dito, tais propostas de observação orientaram a análise das entrevistas, sendo recolhidos alguns fragmentos não exaustivos para a discussão que será apresentada a seguir.

Importante ressaltar que, considerando-se a lógica psicanalítica, não se pretende pensar as observações a partir de uma relação binária de causa e efeito, posto reconhecermos que aquilo que faz marca constitutiva para um sujeito pode não fazer para outro. Todavia, faz-se a aposta de que os aspectos que foram observados possam ser tomados como sinais, indicadores dos processos em curso na sua constituição e de seus jogos de posição diante do Outro primordial (Bergès \& Balbo, 2002).

\section{Resultados da pesquisa: uma leitura a partir do estabelecimento da demanda e dos processos primordiais de identificação}

A formulação da demanda representa um tempo primordial da constituição do sujeito e sua inserção nos campos da linguagem e do desejo; inclui, ainda, problemáticas relacionadas aos tempos especulares e às identificações provenientes das relações primordiais mãe-bebê, colocando em jogo as operações simbólicas relacionadas às dimensões de presença e ausência do Outro primordial. Sua construção se faz pela via de implicação do semelhante que dele se ocupa, através do reconhecimento e atribuições de sentido aos movimentos pulsionais empreendidos pelo bebê. Considera-se que tal reconhecimento estará na base do desenvolvimento simbólico e social posterior.

Em seus "Três ensaios sobre a teoria da sexualidade", Freud (1905/1996) aponta que o trato da criança pela pessoa que a assiste é, para aquela, uma fonte incessante de excitação, até porque esta, que usualmente é a mãe, contempla a criança com os sentimentos derivados de sua própria vida sexual. Que a mãe se horrorize caso desconfie que tais expressões de ternura servem, no fundo, como força motriz para a pulsão sexual de seu filho, não invalida a suma importância das 
pulsões para a vida anímica como um todo, para todas as realizações éticas e psíquicas. Na verdade, segundo Freud (1905/1996), ela até mesmo se pouparia das autorrecriminações ao ver que, quando ensina seu filho a amar, está apenas cumprindo sua tarefa.

Freud (1905/1996, 1915/2004) indica, ainda, que as zonas erógenas se constituem a partir do substrato orgânico, mas vão progressivamente se afastando e se tornando independentes, levando a uma edificação da sexualidade e do corpo erógeno. Utilizou o exemplo da sucção, que inicialmente serve à alimentação pelo seio, mas que passa à atividade erotizada. A boca torna-se uma zona erógena através da repetição do movimento de sucção não mais como ato reflexo, nem restrito à função de alimentação, mas por prazer, portanto, uma atividade pulsional; investido agora pelo prazer desta experiência, passa a sugar o polegar, a chupeta ou o seio da mãe sem que, necessariamente, sua ação se relacione à satisfação de uma necessidade. Assim, a vida sexual infantil exibe componentes que desde o início envolvem outras pessoas como objetos sexuais. Freud (1905/1996) acrescenta que dos primeiros e mais importantes de todos os vínculos sexuais, resta, mesmo depois que a atividade sexual se separa da nutrição, uma parcela significativa que auxilia a preparar a escolha do objeto.

Deste modo, a partir de seu investimento, a mãe, ou aquele que executa sua função, tornará possível a inscrição de traços primordiais que marcam o 
corpo e o psiquismo da criança, instaurando os registros do desejo e da demanda. Em outras palavras, a dependência de Outro para satisfazer as necessidades aliada à erotização do corpo do bebê abrem caminho para a organização das fronteiras do Eu e a constituição de um lugar desejante. Assim, a alimentação pode ser considerada uma importante via de articulação entre o somático e o psíquico, em que os componentes da pulsão relacionados à força e à pressão se associam à finalidade e à escolha de objeto. Alimentar-se e ser alimentado coloca em curso o jogo de posições subjetivas da criança e de sua mãe.

Os seguintes fragmentos, colhidos da fala das mães durante a aplicação da AP3, podem ilustrar estes jogos da criança e da mãe em suas relações com possíveis dificuldades no estabelecimento da demanda: "ele não quer nada"; "se esquece de comer"; "nunca pede comida"; "engasga-se com comida seca"; "bota pra fora"; "sempre foi pouca e, quando quer engordar, adoece"; "quando ele tá ficando cheio, fica doente de novo". Eles indicam também a trama especular onde se estruturam, por exemplo, alguns dos sintomas alimentares na infância. Segundo Crespin (2004), nas histórias alimentares dos primeiros anos de vida, o problema raramente é o que se passa no estômago ou na mamadeira: "A proximidade da oralidade ao estritamente do registro alimentar, com suas conotações médicas, expõe muitas vezes os médicos ao risco de se contentarem pura e simplesmente com o lado mais superficial da necessidade, negligenciando sua dimensão simbólica" (Crespin, 2004, p. 34).

Em um caso específico de aplicação da AP3, uma mãe afirma que levou a filha à instituição porque "ela dá muito trabalho para comer". Relatou que dava de mamar de modo "forçado, pois não sabia como fazer". E ainda sobre o período da amamentação, afirma: "eu não sentia vontade de comer e achava que minha filh a também não". Destacam-se destes fragmentos indicações quanto às dificuldades nos processos de identificação e separação mãe e filha. O sentimento de confiança da mãe na capacidade de realizar sua função parece ter atingido uma identificação com a criança que a impede de diferenciar as necessidades da filha de suas próprias necessidades.

A mãe expressou sua preocupação com relação à recusa alimentar, afirmando: "acho que não tenho mais controle. Acho que eu acostumei ela assim e não sei mais consertar"; e continua: "se ela não quisesse comer, dava leite. E agora pra comer comida de panela é mais difícil'. O que estava em jogo nesta recusa e na falta de confiabilidade da mãe em seu cuidado? Estaria a criança resistindo a uma forma de especularização que obtura a sua condição desejante? 
Desde o início da entrevista de aplicação da AP3 a mãe trouxe uma queixa à entrevistadora em relação às atitudes da filha, afirmando que ela estava muito agressiva. Quando questionada a respeito de possíveis motivos para esse tipo de comportamento, constrói uma interpretação onde supõe que o comportamento da filha seja um reflexo das constantes brigas entre ela e o marido, assistidas pela menina. Não se percebeu, entretanto, durante todo o tempo da avaliação, nenhuma atitude agressiva por parte da criança. A mãe prossegue: "na escola, não dá trabalho, mas comigo ela dá; faz de tudo para me tirar do sério". A criança, segundo sua mãe, pede para ela não brigar com o pai. Acrescentou que, quando está triste, a filha conversa com ela, o que a surpreende, "por causa da idade". A ambivalência no laço com a mãe indicaria ecos de uma separação que não pode ainda se efetivar? Que condições poderiam estar relacionadas aos obstáculos em jogo? As questões relativas ao narcisismo materno?

Em “À guisa de introdução ao narcisismo" (1914/2004), a “sua majestade o bebê" representará para Freud a figura paradigmática do investimento narcísico dos pais sobre a criança. A onipotência dos pais e sua contrapartida, a idealização da criança, devem possibilitar a formação de uma representação do corpo próprio e de uma função identificatória, criando condições para o estabelecimento da relação com o prazer e a realidade.

Ainda a respeito da identificação, Freud (1921/1996) refere que ela constitui a forma mais primitiva e original de um laço emocional com outra pessoa, antes que qualquer escolha sexual de objeto tenha sido feita. Freud também destaca que a identificação é ambivalente desde o início e que se comporta como um derivado da primeira fase da organização libidinal - fase oral. E que a identificação esforça-se ainda por moldar o Eu segundo o aspecto daquele que foi tomado como modelo. O que coaduna com o que ele apresenta nos estudos sobre a melancolia (Freud, 1917/1996), ao afirmar que grande parte da constituição do Eu se dá pela via da identificação, do processo de reconstituição das características do objeto perdido no Eu.

Portanto, complexos caminhos devem ser percorridos antes que o Eu possa representar a perda do objeto e os sentidos relativos a esta. De que condições a criança precisa dispor para apreender a modular seus jogos de posição na relação com este Outro especular, experimentar o prazer, construir os sentidos de realidade? Freud e Ferenczi respondem juntos a esta questão: são necessárias a atribuição de onipotência, a ambivalência, as capacidades de introjetar e 
projetar a compreensão do adulto. Em outras palavras, é necessário um fiador para a representação do objeto (Martins, 2014, pp. 95-96).

Atento às consequências psíquicas dos sentidos apreendidos neste campo de relação da criança com os pais (ou com quem dela se ocupe), Ferenczi (1913/1989a) afirma ser o investimento dos adultos, demonstrado pela suposição da onipotência, aquilo que financiará o primeiro sentido de realidade. A sua curiosa afirmação de que os gestos supersticiosos são resíduos pertencentes a um determinado período do sentido de realidade e aos estágios de onipotência que correspondem à fase de introjeção, permite-nos pensar que a invenção do sentido de realidade (e, acrescentamos, o prazer que deste deriva) não corresponde ao golpe na onipotência. A própria suposição de poder mágico ao gesto já configura um dos sentidos de realidade.

$\mathrm{Na}$ perspectiva winnicottiana sobre o desenvolvimento infantil, a mudança para o princípio de realidade relaciona-se à inestimável capacidade do sujeito de usar um objeto, aceitando-o como exterioridade; mas para ascender ao uso, é necessária antes a relação.

Essa mudança (do relacionamento para o uso) significa que o sujeito destrói o objeto... depois de "o sujeito relaciona-se com o objeto", temos "o sujeito destrói o objeto"(quando se torna externo), e, então, podemos ter "o objeto sobrevive à destruição pelo sujeito". Porque pode haver ou não sobrevivência. Surge assim um novo aspecto na teoria da relação de objeto. O sujeito diz ao objeto: "Eu te destruí" e o objeto ali está, recebendo a comunicação. Daí por diante, o sujeito diz: "Eu te destruí. Eu te amo. Tua sobrevivência à destruição que te fiz sofrer confere valor à tua existência para mim. Enquanto estou te amando, estou permanentemente te destruindo na fantasia" (inconsciente). Aqui começa a fantasia para o indivíduo. O sujeito pode agora usar o objeto que sobreviveu.... Dessa forma, o objeto desenvolve a sua própria autonomia e vida e (se sobrevive) contribui para o sujeito, de acordo com suas próprias propriedades (Winnicott, 1975, p. 126).

A afirmação de que o objeto contribui com suas próprias propriedades possibilita-nos pensar nas condições narcísicas deste Outro para suportar a experiência de separação; ou seja, caminham juntas as experiências de separação e de continuidade na construção das condições de possibilidade para esta perda. Condição anunciada por Winnicott (1975) neste paradoxo: para que se possa prescindir do objeto, é necessário que ele continue existindo como realidade externa, marcado por suas propriedades. Se o objeto se apresenta sem qualidades, sem predicados, diante dele o Eu, por exemplo, silencia, se paralisa, ou mesmo retorna a formas primitivas de comunicação, onde podemos situar algumas patologias do ato e os sintomas corporais e somáticos; e, ainda, a presença de angústias muitos primitivas e de horror, como sugere Souza (2001) ao relacionar os sentidos atribuídos à perda (aqui sinônimo de separação) e seus rumos subjetivos à sua ordem de grandeza e ao momento em que esta experiência pôde ser subjetivada. 
A sistematização destas questões nos leva novamente ao pensamento de Ferenczi, apresentado no texto "A criança mal acolhida e sua pulsão de morte" (1929/1989b), relativo a um grupo de pacientes que, com a perda precoce do gosto pela vida, aparecem como pessoas que, tendo uma capacidade de adaptação insuficiente, perderam também a capacidade de gozar da alegria lá onde realmente ela se oferece, referindo-se a esses casos como neuroses de frustração.

Lacan considerou a frustração o "verdadeiro centro quando se trata de situar as relações primitivas da criança" (Lacan, 1995, p. 66), tomando-a em duas vertentes: por um lado, o objeto real, por outro, o agente. Segundo ele, o que se introduz no par de opostos presença/ausência é o que tende normalmente a adormecer no momento da frustração: quando a mãe simbólica passa a responder ao apelo da criança, segundo os seus próprios critérios, ela se torna real, tornando-se uma potência. As posições se invertem: o objeto se torna simbólico e a mãe se torna real. No momento em que a mãe vira potência e o acesso aos objetos continua dependendo dela, esses, que até então eram objetos de satisfação, tornam-se objetos de dom. O sujeito passa a contar com o capricho do outro e o objeto passa a valer como testemunho do dom oriundo dessa potência. O objeto tem, a partir daí, duas ordens de propriedades, ele é duas vezes objeto possível de satisfação - como anteriormente, satisfaz a uma necessidade, mas também simboliza uma potência favorável (Lacan, 1995, pp. 66-70). Deste modo, para Lacan, o que conta não é a onipotência materna e sim as carências e as decepções que afetam essa onipotência.

Uma mãe, ao ser questionada sobre o modo como a criança solicita a sua alimentação, responde: "tudo ela pede", fazendo referência tanto à comida quanto aos excrementos. Porém, em seguida, ressalta, quanto à comida, que se a filha não pede, ela dá mesmo assim e, quanto aos excrementos: "ela [a filha] pede assim, depois que já fez. na roupa". Durante a entrevista com a mãe, a criança urinou na roupa e não lhe avisou; embaraçado, o irmão comunica à mãe o ocorrido. A mãe balança, discretamente, a cabeça de forma afirmativa para o filho mais velho que a acompanha, mas não se dirige à filha nem comenta o ocorrido. São fragmentos clínicos que sinalizam duas ordens de dificuldades: tomar como dom os objetos que provém da criança e identificar seu pedido como uma demanda a ela dirigida.

Nessas condições, supõe-se que, na recusa alimentar, o que se cria é um vazio. Essa problemática poderia ser situada no nível da 
introjeção das experiências com o mundo externo, ou ainda, da capacidade deste de elaborar sentido às suas perdas, funcionando, como dito anteriormente, como uma espécie de testemunho e fiador da representação. Alimentar e receber o cocô e o xixi fazem parte de uma mesma série significante compreendida aqui em referência ao narcisismo materno e ao estabelecimento de uma ordem de filiação.

Encontramos em grande parte das entrevistas o relato de situações que nos fizeram supor uma espécie de dificuldade de conferir à criança um lugar particular na ordem de filiação. Mas, no caso de uma mãe de gêmeos esta situação chega a um paroxismo: quando questionada, a mãe respondia no plural, incluindo o outro filho, iguais não apenas na aparência, mas, também, nas mesmas problemáticas.

\section{Considerações finais}

A partir da compreensão dos sintomas alimentares como uma formação do inconsciente e como um sinalizador da posição da criança no discurso e no desejo dos seus pais, buscou-se discutir alguns fragmentos de aplicações da AP3, especificamente aqueles referentes às relações entre o quadro de desnutrição e possíveis impasses no estabelecimento da demanda, considerando-a como uma operação que coloca em jogo os processos de identificação primários e o narcisismo materno.

A clínica com crianças pequenas produz indagações a respeito dos primórdios da constituição psíquica. $\mathrm{O}$ trabalho com bebês faz perceber que esses mecanismos estão em primeiro plano nessa época da vida, e que o estabelecimento da demanda vincula-se fortemente à criação da imagem ficcional para a criança, à qual ela se identifica inicialmente. Percebe-se, portanto, a importância de inserir as ações do bebê em um circuito pulsional e simbólico, possibilitando a construção de processos identificatórios fundamentais às operações de estabelecimento de demandas na criança; para tanto, é necessária a suposição de um sujeito, sua antecipação. O narcisismo materno é uma espécie de matriz simbólica a partir da qual o circuito pulsional e desejante da criança será traçado, propusera Freud (1914/2004). Deste modo, faz-se necessário estabelecer possíveis relações entre as condições narcísicas (e libidinais) destas mães para realizar as operações fundamentais ao estabelecimento da 
demanda. Como afirma Lacan (1992, p. 202), "a demanda oral tem outro sentido para além da satisfação da fome. Ela é demanda sexual", posto que "não é apenas da boa vontade do Outro que o sujeito primitivo tem que se alimentar, mas simplesmente do corpo daquele que o alimenta". Este ponto não pôde ser debatido mais amplamente neste artigo, no entanto, é importante sinalizar que, diante do desamparo dessas mães em suas precárias situações de vida, a demanda da criança é lida numa gramática onde o gesto da criança e seu pedido são considerados como mais um excedente, um impossível de responder. De um lado, a impossibilidade da mãe de tornar o gesto da criança significativo, de outro, a recusa da criança em se alimentar como uma tentativa para salvaguardar o seu desejo.

Onde poderia estar a mãe nessas condições? O que dizer sobre os seus investimentos libidinais diante de sua própria privação material e psíquica? Se de um lado encontramos as crianças empobrecidas em seu brincar, com uma linguagem predominantemente gestual e uma fala com poucos vocábulos; de outro encontramos o silêncio das mães, rostos em suas aparências desvitalizadas, às vezes se expressando em narrativas estancadas por afetos que faziam supor a presença de uma vergonha de si mesmas. O quadro encontrado remetia, algumas vezes, ao complexo da mãe morta, descrito por Green (1988), onde, segundo ele, a angústia do abandono nunca se deposita sobre um contexto sanguinário. No lugar do vermelho, o preto e o branco do luto: "preto como a depressão grave, branco como nos estados do vazio.... A mãe morta... é uma mãe que permanece viva, mas que está, por assim dizer, morta psiquicamente aos olhos da pequena criança de quem ela cuida" (p. 243). Cabe ressaltar que no quadro descrito por Green (1988) o preto, o branco e o vazio são secundários, correspondendo a um investimento que foi retirado, o que não ocorre, necessariamente, nos casos onde sobrevém uma angústia primitiva.

Quais as possíveis consequências para o modo como essa criança relacionar-se-á com o mundo da linguagem e para o modo como estabelece suas relações de pertencimento à cultura? Como podem ser sustentadas as condições para a criação e transformação da ordem subjetiva?

Pode-se ainda observar que o brincar nas experiências-limite, a fome considerada uma destas, amputado pela pregnância do real, distancia-se da ilusão criadora responsável pelo sentimento de pertencimento à ordem da cultura. $\mathrm{O}$ agir criativo da criança (e de sua mãe) e seu ingresso em um registro para além da dor são correlativamente dependentes da sustentação dos laços sociais dos seus cuidadores por uma rede familiar social e/ ou comunitária. Entendemos também que as 
condições para a subjetivação desta experiência são, por vezes, preservadas nos casos em que a mãe é reconhecida em seus direitos e na sua capacidade de estimar e desejar (Martins et al., 2011).

O processo de aplicação do instrumento AP3 constitui um meio de observação de indicadores clínicos a respeito do desenvolvimento infantil. O uso de instrumentos como esse é controverso e tem levantado discordâncias. Nessa direção, Kupfer e Voltolini (2005) referem que o uso de indicadores se justifica pela observação de que a presença de um sujeito psíquico só é passível de constatação a partir dos efeitos indiretos que ela produz.

De acordo com Crespin (2004), não é possível antecipar a maneira pela qual o acontecimento será tratado pelo sujeito, isto é, não sabemos de antemão o que um acontecimento desencadeará num dado sujeito. Nesse sentido, a avaliação realizada pela AP3 pode ser vista como uma forma de observar o curso deste processo, seus impasses e sofrimentos correlatos que uma criança pode apresentar desde cedo, possibilitando, a partir daí, uma intervenção.

A atividade simbólica da criança que ainda não fala traduz-se no nível das funções corporais. A mediação do Outro pela linguagem, em seu amplo sentido, pode envelopar, como propõe Anzieu (1989), as manifestações orgânicas, dando-lhe condições para a constituição de fronteiras psíquicas fundamentais para a criança prosseguir rumo à sua subjetivação. Deste modo, é preciso, primeiramente, apostar na singularidade, supor um sujeito, ficcionalizá-lo. Como indica Teperman (2005), afirmar que o bebê é um ser de linguagem não implica que ele já tenha um conhecimento da língua a que está submetido. Mais determinante é o seu futuro falante já marcá-lo como "promessa", e é a partir desta promessa que mães, por exemplo, falam com seus bebês recém-nascidos.

Um dos principais papéis do analista na instituição seria, então, o de garantir uma prática clínica na qual o lugar do sujeito seja, igualmente, suposto e sinalizado. É necessário contribuir com as possibilidades de se produzir deslocamentos na posição de identificação com os significantes que obstaculizam esta posição, sejam aqueles relativos à história pessoal destes pais, sejam outros marcados pelos diagnósticos institucionais. $\mathrm{O}$ analista, em seu trabalho de escuta (e espera), como afirma Figueiredo (1996), poderá, com clareza de seu propósito, por em marcha um processo associativo capaz de abrir para o sujeito novas possibilidades de significação.

Relacionada aos modos de viver civilizatórios e à economia libidinal dos sujeitos, a alimentação é pensada por Freud (1895/1996, 1905/1996, 1930/1996) como expressão paradigmática do laço humano com a cultura. Situado nas fronteiras entre o somático e o psíquico, o ato de alimentar associa a fome ao desejo em sua dimensão pulsional, definindo assim as matrizes de constituição do psíquico. 
FOOD DEPRIVATION AND IMPACTS ON PSYCHIC CONSTITUTION: A STUDY

ABOUT THE ESTABLIS HMENT OF THE DEMAND IN CHILDREN DIAGNOSED WITH MALNUTRITION THROUGH THE APPLICATION OF PSYCHOANALYTICAL EVALUATION AT THE AGE OF THREE

\begin{abstract}
This article is part of a line of studies whose purpose is to ponder the experience of hunger in childhood and its possible connections with the psychic constitution process. Some results of the application of the Avaliagano Psicanalitica aos 3 anos (AP3) instrument, applied in a third sector institution which is reference in the treatment of infant malnutrition in the city of Fortaleza, Ceara state, Brazil, will be presented. With the analysis, it was possible to relate the prevalence of malnutrition with the processes of establishment of demand, taking into account that the privation of food may be paradoxically correlated to its refusal.
\end{abstract}

Index terms: child malnutrition; bunger; demand; food refusal; psychoanalytical evaluation at the age of 3 .

PRIVACIÓN DEL ALIMENTO E INCIDENCIAS EN LA CONSTITUCIÓN PSÍQUICA: UNA INVESTIGACIÓN ACERCA DEL ESTABLECIMIENTO DE LA DEMANDA EN NIÑOS CON DIAGNÓSTICO DE DESNUTRICIÓN A PARTIR DE LA APLICACIÓN DE LA EVALUACIÓN PSICOANALÍTICA A LOS 3 AÑOS

\title{
RESUMEN
}

Este trabajo es parte de una línea de investigaciones con el objetivo de reflexionar sobre la experiencia del hambre en la infancia y su posible relación con el proceso de constitución psíquica. Se presentarán algunos resultados de la aplicación de la evaluación psicoanalitica a los 3 años, que tuvo lugar en institución del tercer sector de la ciudad de Fortaleza, en Ceará, Brasil, de referencia en el tratamiento de la desnutrición infantil. Desde el análisis, fue posible relacionar la prevalencia de desnutrición con el establecimiento de demanda, teniendo en cuenta que la privación de alimentos puede correlacionarse, paradójicamente, con su rechąo.

Palabras clave: desnutrición infantil; hambre; demanda; rechazo del alimento; evaluación psicoanalitica a los 3 años.

\section{REFERÊNCIAS}

Anzieu, D. (1989). O eu-pele. São Paulo, SP: Casa do Psicólogo.

Bergès, J., \& Balbo, G. (2002). Jogo de posiçôes da mãe e da criança: ensaio sobre o transitivismo. Porto Alegre, RS: CMC.

Bernardino, L. M. F. (2006). A abordagem psicanalítica do desenvolvimento infantil e suas vicissitudes. In L. M. F. Bernardino (Org.), O que a Psicanálise pode ensinar sobre a criança sujeito em constituição (pp. 19-41). São Paulo, SP: Escuta.

Bernardino, L. M. F., \& Vaz, B. G. (2015). Avaliação de crianças pequenas em processo de educação inclusiva através do protocolo AP3. Educação, 38(2), 193-202. Recuperado de http:// bit.ly/2jQyyFW.

Brasil. (2005). Manual de atendimento da criança com desnutrição grave em nível hospitalar. Brasília, DF: Ministério da Saúde.

Brasil. (2012). Política Nacional de Alimentação e Nutrição. Brasília, DF: Ministério da Saúde. Cavalcante e Silva, A. (1995). Evolução da saúde da criança no Ceará: um retrato de dois momentos 1987-1994. Dissertação de Mestrado, Faculdade de Medicina, Universidade Federal do Ceará, Fortaleza, CE. 
Cavalcante e Silva, A., Correia, L. L., Campos, J. S., Andrade, F. M., Silveira D. M., Leite, Á. J. et al. (2015). Reducing child mortality: the contribution of Ceará state, northeast of Brazil, on achieving the millennium development Goal 4 in Brazil. Matern Child Health Journal, 19(4), 700-706.

Carvalho, A. S. (2011). Desnutrição infantil e os impasses nas trocas alimentares: uma discussão psicanalitica. Dissertação de Mestrado, Programa de Pós-Graduação em Psicologia, Universidade de Fortaleza, Fortaleza, CE.

Carvalho, A. S., Lima, M. C. P., \& Martins, K. P. H. (2013a). As problemáticas alimentares e a desnutrição na infância: contribuiçôes psicanalíticas. Estilos da Clínica, 18(2), 372-386. Recuperado de http://bit.ly/2kGZAxz

Carvalho, A. S., Lima, M. C. P., \& Martins, K. P. H. (2013b). Desnutrição infantil e a relação mãe-bebê: uma discussão psicanalítica. In M.-C. Busnel, \& R. G. Melgaço (Orgs.), O bebê e as palavras: uma visão transdisciplinar sobre o bebê (pp. 270-285). São Paulo, SP: Instituto Langage.

Correia, L. L., Silva, A. C., Campos, J. S., Andrade, F. M. O., Silveira, D. M. I., Machado, M. M. T. et al. (2014a). Metodologia das Pesquisas Populacionais de Saúde Materno-Infantil: uma série transversal realizada no Estado do Ceará de 1987 a 2007. Revista Brasileira de Saúde Materno Infantil, 14(4), 353-362. Recuperado de http://bit.ly/2ktH8I2

Correia, L. L., Silva, A. C., Campos, J. S., Andrade, F. M. O., Machado, M. M. T., Lindsay A. C. et al. (2014b). Prevalence and determinants of child undernutrition and stunting in semiarid region of Brazil. Revista de Saúde Pública, 48(1), 19-28. Recuperado de http://bit.ly/2lgC5P2 Crespin, G. C. (2004). A clínica precoce: o nascimento do humano. São Paulo, SP: Casa do Psicólogo.

De Césaris, D. M. C. (2013). O uso dos instrumentos IRDI e AP3 no acompanhamento da constituição da imagem corporallespecular de crianças em centros de educação infantil. Tese de Doutorado, Universidade de São Paulo, São Paulo, SP.

Di Paolo, A., Lerner, R., \& Kupfer, M. (2008). Avaliação Psicanalítica aos 3 anos: desdobramentos e novas contribuiçóes. In Anais, 7. Colóquio Formação de Profissionais e a Criança-sujeito, 2008, São Paulo, SP. São Paulo, SP: Laboratório de estudos e pesquisas psicanalíticas e educacionais sobre a infância (LEPSI) da Universidade de São Paulo. Recuperado de http://bit.ly/215rUuN

Ferenczi, S. (1989a). O desenvolvimento dos sentidos de realidade e seus estágios. In S. Ferenczi, Escritos psicanalíticos 1909-1933 (pp. 74-88). Rio de Janeiro, RJ: Livraria Taurus. (Trabalho original publicado em 1913)

Ferenczi, S. (1989b). A criança mal-acolhida e sua pulsão de morte. In S. Ferenczi, Escritos psicanalíticos 1909-1933 (pp. 313-317). Rio de Janeiro, RJ: Livraria Taurus. (Trabalho original publicado em 1929)

Figueiredo, A. (1996). Por uma psicanálise possível nos serviços de saúde mental. Cadernos IPUB, 2(3), 99-113.

Food and Agriculture Organization of the united nations (FAO), International Fund for Agricultural Development (IFAD), \& World Food Programme (WFP). (2015). The State of Food Insecurity in the World 2015: meeting the 2015 international hunger targets: taking stock of uneven progress. Rome: FAO. Recuperado de

Freud, S. (1996). Projeto para uma psicologia científica. In S. Freud,, Edição standard brasileira das obras psicológicas completas de Sigmund Freud Freud (J. Salomão, trad., Vol. 1., pp. 335-469). Rio de Janeiro, RJ: Imago. (Trabalho original publicado em 1895)

Freud, S. (1996). Três ensaios sobre a teoria da sexualidade. In S. Freud, Edição standard brasileira das obras psicológicas completas de Sigmund Freud (J. Salomão, trad., Vol. 7, pp. 119-311). Rio de Janeiro, RJ: Imago. (Trabalho original publicado em 1905)

636 Estilos clin., São Paulo, v. 21, n. 3, set./dez. 2016, 618-638. 
Freud, S. (1996). Luto e melancolia. In S. Freud,, Ediçâo standard brasileira das obras psicológicas completas de Sigmund Freud Freud (J. Salomão, trad., Vol. 14., pp. 243-266). Rio de Janeiro, RJ: Imago. (Trabalho original publicado em 1917)

Freud, S. (1996). Psicologia de grupo e análise do ego. In S. Freud,, Edição standard brasileira das obras psicológicas completas de Sigmund Freud Freud (J. Salomão, trad., Vol. 18, pp. 79-154). Rio de Janeiro, RJ: Imago. (Trabalho original publicado em 1921)

Freud, S. (1996). O mal-estar na civilização. In S. Freud, Edição standard brasileira das obras psicológicas completas de Sigmund Freud (J. Salomão, trad., Vol. 21, pp. 65-148). Rio de Janeiro, RJ: Imago. (Trabalho original publicado em 1930)

Freud, S. (2004). À guisa de introdução ao narcisismo. In S. Freud, Obras psicológicas de Sigmund Freud: escritos sobre a psicologia do inconsciente (L. A. Hanns, trad., Vol. 1, pp. 95-131). Rio de Janeiro, RJ: Imago. (Trabalho original publicado em 1914)

Freud, S. (2004). Pulsões e destinos da pulsão. In S. Freud, Obras psicológicas de Sigmund Freud: escritos sobre a psicologia do inconsciente (L. A. Hanns, trad., Vol. 1, pp. 133-173). Rio de Janeiro, RJ: Imago. (Trabalho original publicado em 1915)

Green, A. (1988). A mãe morta. In A. Green, Narcisismo de vida, narcisismo de morte (pp. 239273). São Paulo, SP: Escuta.

Jerusalinsky, A. N. (2008). Considerações acerca da Avaliação Psicanalítica de Crianças de Três Anos - AP3. In R. Lerner, \& M. C. M. Kupfer (Orgs.). Psicanálise com crianças: clínica e pesquisa. São Paulo, SP: Escuta.

Kupfer, M. C. M., Jerusalinsky, A. N., Bernardino, L. M. F., Wanderley, D., Rocha, P. S. B., Molina, S. E. et al. (2010). Valor preditivo de indicadores clínicos de risco para o desenvolvimento infantil: um estudo a partir da teoria psicanalítica. Revista Latinoamericana de Psicopatologia Fundamental, 13(1), 31-52. Recuperado de http://bit.ly/2knzGmv

Kupfer, M. C. M., \& Voltolini, R. (2005). Uso de indicadores em pesquisa de orientação psicanalítica: um debate conceitual. Psicologia: Teoria e Pesquisa, 21(3), 359-364. Recuperado de http://bit.ly/2lHEHXp

Kupfer, M. C. M., Jerusalinsky, A. N., Infante, D., Bernardino, L. M. F. et al. (2008). Roteiro para a Avaliação Psicanalítica de Crianças de Três Anos - AP3. In Lerner, R.; Kupfer, M. (Orgs.). Psicanálise com crianças: clínica e pesquisa (pp. 137-147). São Paulo, SP: Escuta.

Lacan, J. (1992). Demanda e desejo nas fases oral e anal. In J. Lacan, O seminário, livro 8: a transferência, 1960-1961 (D. Estrada, trad., pp. 197-209). Rio de Janeiro, RJ: Jorge Zahar.

Lacan, J. (1995). A dialética da frustração. In J. Lacan, O seminário, livro 4: a relação de objeto, 1956 (D. Estrada, trad., pp. 59-75). Rio de Janeiro, RJ: Jorge Zahar.

Lei no 8.080, de 19 de setembro de 1990. (1990). Dispóe sobre as condiçóes para promoção, proteção e recuperação da saúde, a organização e o funcionamento dos serviços correspondentes e dá outras providências. Diário Oficial da União, Brasília, DF: Poder Executivo. Recuperado de http://bit.ly/1UVpr2U.

Martins, K. (2006). Profetas da chuva. Fortaleza, CE: Tempo d'Imagem.

Martins, K. (2010). Os impactos da experiência da fome na constituição do psiquismo. In Anais, 1. Congresso de Intervençóes Psicanaliticas na Clínica e no Social: a experiência da fome na clínica e na cultura, 2010, Fortaleza, CE. Fortaleza, CE: Laboratório de Estudos e Intervençôes Psicanalíticas na Clínica e no Social/Programa de Pós-Graduação em Psicologia da Universidade de Fortaleza (UNIFOR).

Martins, K. (2014). Sertão e melancolia: espaços e fronteiras. Curitiba, PR: Appris.

Martins, K., Barbosa, C., Pontes, F., Martins, L., Arruda, L., Barros, M. et al. (2011). Infância e privação: a fome, o silêncio e a vontade de viver. In C. Pinheiro, J. Carvalho, \& Silva, M. 
(Orgs.). Estudos psicanalíticos na clinica e no social (pp. 79-97). Fortaleza, CE: Imprensa Universitária.

Organização das Naçôes Unidas (ONU). (2001). Declaração do Milénio de 2000. Lisboa: ONU.

Souza, O. (2001). Notas sobre algumas das diferenças na valorização dos afetos nas teorias psicanalíticas. In B. Bezerra Jr., \& C. Plastino (Orgs.). Corpo, afeto, linguagem: a questão do sentido hoje (pp. 285-298). Rio de Janeiro, RJ: Rios Ambiciosos.

Teperman, D. W. (2005). Clínica psicanalítica com bebês: uma intervenção a tempo. São Paulo, SP: Casa do Psicólogo, Fapesp.

Winnicott, D. (1975). O brincar e a realidade. Rio de Janeiro, RJ: Imago.

World Health Organization (WHO), United Nations Children's Fund (Unicef). (2009). WHO child growth standards and the identification of severe acute malnutrition in infants and children. Geneva: World Health Organization.

\section{NOTAS}

1. A pesquisa, financiada pela Coordenação de Aperfeiçoamento de Pessoal de Nível Superior (Capes), foi submetida à apreciação do Comitê de Ética em Pesquisa (CEP) da Universidade Federal do Ceará (UFC) sob o número 197.277/2013.

2. A avaliação nutricional utilizada como triagem para a entrada das crianças no Iprede é realizada com o instrumento indicado pela OMS denominado WHO Anthro, disponível em: http://www.who.int/childgrowth/software. A avaliação baseia-se no escore $\mathrm{Z}$ e nas relações entre peso/idade, altura/idade e peso/altura.

kphm@uol.com.br

Avenida da Universidade, 2762 60020-180 - Fortaleza - CE - Brasil.

celina.lima@unifor.br

Avenida Washington Soares, 1321 60811-905 - Fortaleza - CE - Brasil.

gabrielamsimao@hotmail.com

Avenida da Universidade, 2762 60020-180 - Fortaleza - CE - Brasil.

allanratts@gmail.com

Avenida da Universidade, 2762 60020-180 - Fortaleza - CE - Brasil.

Recebido em julho/2016. Aceito em novembro/2016.

638 Estilos clin., São Paulo, v. 21, n. 3, set./dez. 2016, 618-638. 